\title{
Vibration Behavior during Underground Drilling Based on an Innovative Measurement Method and the Application
}

\author{
Peng Cheng, ${ }^{1,2,3}$ Wenlong Zhang $\mathbb{D}^{1}{ }^{1}$ Wenzhou $\mathrm{Li}^{2,3}$ Jie He, ${ }^{1,2,3}$ and Youliang Feng \\ ${ }^{1}$ School of Energy and Mining Engineering, China University of Mining and Technology (Beijing), Beijing 10083, China \\ ${ }^{2}$ Coal Mining and Designing Department, Tiandi Science and Technology Co., Ltd., Beijing 100013, China \\ ${ }^{3}$ CCTEG Coal Mining Research Institute, Beijing 100013, China
}

Correspondence should be addressed to Wenlong Zhang; wenlong0523@163.com

Received 16 June 2021; Accepted 15 July 2021; Published 4 August 2021

Academic Editor: Fan Deyuan

Copyright (C) 2021 Peng Cheng et al. This is an open access article distributed under the Creative Commons Attribution License, which permits unrestricted use, distribution, and reproduction in any medium, provided the original work is properly cited.

Pressure relief drilling is one of the most common techniques to reduce the impact of rock burst, but the useful dynamic phenomena in the drilling process are ignored due to the lack of corresponding technical methods. Based on the fact, an innovative measurement method for vibration signals during the drilling construction by pneumatic drill rig is presented in this study. The acquisition and analysis of vibration signals show that the vibration information can reflect the drilling depth, the amplitude of different depth can reflect the pressure, and the vibration events of different depths can reflect the pressure relief effect. The method proposed in the study is of great significance to the supervision of the relief work quantity, the disclosure of the pressure situation, and the evaluation of the pressure relief effect.

\section{Introduction}

Coal is the main energy source in China at present, and it will not change for quite a long time in the future. Most of the coal mines are underground [1], which means more mining risks are compared to open pit mining methods in home and abroad. There are still many losses and casualties although accidents have decreased in recent years in China due to the effective technology and management [2]. Rock burst is one of the dynamic disasters in coal mine, which has a high degree of risk [3]. It releases so much pressure in a short time that hundreds or even thousands of roadways are damaged and hundreds of people are instantaneously killed. Several major rock burst accidents have occurred in China recently, such as Yuncheng "10.20," Xinjulong "2.22," and Tangshan "8.2", which caused huge adverse effects [4]. Therefore, the study of rock burst has become one of the hot spots and difficulties in coal mine research $[5,6]$.

The original research of rock burst mainly focuses on its occurrence mechanisms [7], monitoring methods [8,9], early warning $[6,10]$, and control measures $[11]$. Dozens of rock burst mechanisms have been developed to explain the occurrence of rock burst to a certain extent, including dynamic and static load principle [12], start-up theory [13], energy theory [14], strength theory [15], and butterfly rock burst mechanism [16], and the effect of dynamic load- and stress-induced instability is highly recognized [17, 18]. Normally, the monitoring and control of rock burst are carried out separately [19], which are mainly based on the principles of microseism. The monitoring method include microseismic monitoring [20,21], acoustic emission monitoring [22, 23], stress monitoring [24], electromagnetic radiation [25], and new detecting method such as isotope tracing to detect the roof strata [26], which warn the occurrence of rock burst early according to the abnormal indicators [27]. The control measures mainly include pressure relief drilling [11], roof stratum blasting [11, 28], hydraulic fracturing [29], hydraulic reaming [30], roadway optimization [31], and surrounding rock stability control technology [32], which are mainly based on the principles proposed by the mechanism to reduce the risk of rock burst. The pressure relief drilling is the most common in these measures, but it is only used for pressure relief, and the dynamic phenomena such as stuck drilling [33], suction 
drilling [34], and coal vibration events $[9,35]$ which occurred during the drilling process are completely ignored; however, these phenomena may precisely reflect the risk degree of disaster at the drilling position [36, 37].

In fact, the generation and transmission principle of vibration signal during the construction process of pressure relief drilling is mainly analyzed and demonstrated in our last study [38]. The vibration signals of the hydraulic drilling rig system are also collected and verified, which shows that the result is excellent. In this paper, the quantitative analysis of the drilling signals collected by the hydraulic drilling rig is carried out, and the index disclosure is verified. The results show that the vibration signal acquisition method is suitable for the hydraulic drilling rig, while whether the method is suitable for other drilling tools has not been more verified, and if it is still valid under other construction conditions or other drilling systems needs further research.

In this study, the monitoring results using hand-held pneumatic drill rig in different construction environments show that the drilling depth can still be reflected by the amplitude group, the pressure curve of different depths can also reflect the pressure of different depths, and the pressure relief effect of drilling can also be reflected by the number of coal vibration events of different depths. This technology makes full use of the vibration signal collected during the construction process of pressure relief drilling, which achieves the purpose of multipurpose of one hole. Even more, it may directly replace the drilling cuttings' method [39, 40], which will reduce a lot of engineering cost and save some manpower.

\section{Method}

The test is carried out on the side of 3306 track gateway in a coal mine of Shandong Province, China, which monitors the vibration signal during the construction of the pressure relief drilling hole. The gateway buried depth is about $900 \mathrm{~m}$, the coal seam has weak rock burst tendency, and there are some hard rocks in the roof rock stratum. The drilling system consists of a hand-held pneumatic drilling rig and several drill pipes, and the former is controlled by one worker and the latter is held by another for connection while drilling (Figure 1). A new drill pipe is installed on the drilling rig and connected to the drilled drill pipe with a nut so as to continue drilling after the previous one is constructed. The power of the drilling rig is constant due to the fixed air pressure value. The length of each drill pipe is $2 \mathrm{~m}$, so the depth of the drilling is increased by $2 \mathrm{~m}$. The designed drilling depth is $20 \mathrm{~m}$, which means that it requires ten drill pipes, and the designed diameter is $150 \mathrm{~mm}$, which is considered effective in the practice of many mines.

The hardware part of the vibration monitoring system used in the test includes a gathering device, three detectors, and some transmission cable. The detector receives the vibration signals generated during the drilling process and transmits them to the gathering device through the transmission cable, where they are converted into voltage signals and stored in the hard disk installed in the gathering device. The parameters of the detector and the gathering device are shown in Tables 1 and 2, respectively. The detector adopts fast plug-in high-frequency acquisition moving coil speed detector, with sensitivity of $100 \mathrm{~V} / \mathrm{m} / \mathrm{s}$, maximum transmission distance of $50 \mathrm{~m}$, vibration acceleration of $50 \mathrm{~m} / \mathrm{s}^{2}$, and peak acceleration of $500 \mathrm{~m} / \mathrm{s}^{2}$. The gathering device can be connected with 1 3 detectors, the working voltage is $3.6 \mathrm{mV}$, the battery can work for 96 hours continuously, and the vibration waveform data is stored every $4 \mathrm{~s}$. In this test, the three detectors are set at $1 \mathrm{~m}$ (named $1 \#$ detector), $3 \mathrm{~m}$ (named 2\# detector), and $5 \mathrm{~m}$ (named 3\# detector) away from the borehole and continuously collect signals during drilling.

\section{Results}

The data stored in the hard disk are output and combined to form a curve of amplitude varying with drilling time, which is the waveform of vibration signal generated during drilling pressure relief hole. Take the data measured by $3 \#$ detector as an example, and the vibration waveform is shown in Figure 2, from which it can be seen that the amplitude of vibration signal is not always constant, but fluctuates with time. In order to observe the change of waveform more clearly, the waveform at the abrupt change of amplitude is enlarged, such as the waveform at about $46,800 \mathrm{~ms}$ and $125,600 \mathrm{~ms}$, and the larger images are shown in Figures 2(a) and 2(b), respectively. The amplitude in Figure 2(a) fluctuates greatly in about $0.25 \mathrm{~s}$, which increases by 9 times in a short time and then quickly falls back to the normal amplitude level. This kind of waveform is caused by the sudden release of pressure in the coal seam, which is called vibration event. The fluctuation time of amplitude in Figure 2(b) lasts about $1.5 \mathrm{~s}$, which is longer than vibration event, and the change of the waveform is gentle. This kind of waveform is caused by temporary drilling difficulties, which is called sticking.

Use the maximum amplitude which were read every $4 \mathrm{~s}$ from the waveform measured by $1 \#$ detector, $2 \#$ detector, and 3\# detector, respectively, as the ordinate and use the drilling time as the abscissa to make the variation diagram (Figures 3(a)-3(c)) of the maximum amplitude with time. Because the amplitude of sound wave attenuates with the increase of detection distance, the amplitude values measured by three detectors at the same time are different, as shown in Figures 3(a)-3(c). Nevertheless, the trend of amplitude change with time detected by the three detectors is basically similar. For example, the vibration waves with the largest amplitude appear at 16:30, and there were 13 sets of amplitude group in all the three curves.

In order to show the drilling distance more accurately, the ordinates of the three figures in Figure 3 are reduced to form clearer pictures, which were shown in Figures 4(a)-4(c). The coal seam vibrates obviously during drilling and vibrates slightly when the drilling is interrupted or the drill pipes are connected, so there are obvious amplitude groups composed of larger amplitude and intermission composed of smaller amplitude in the curve of amplitude changing with time. It can be seen that there are 13 sets of amplitude group and 12 intermissions in the three curves of Figures 4(a)-4(c). 


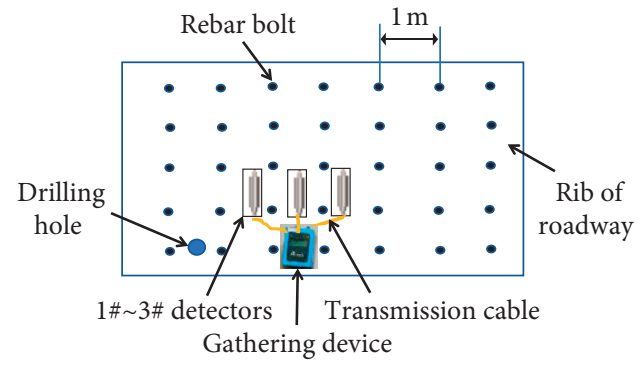

(a)

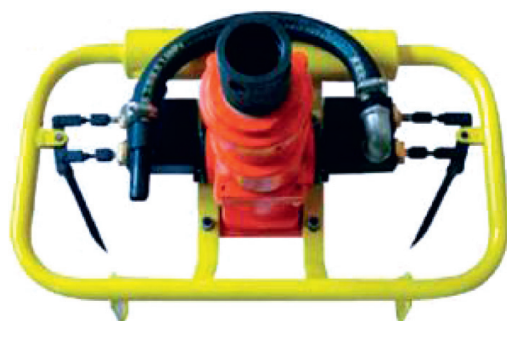

(b)

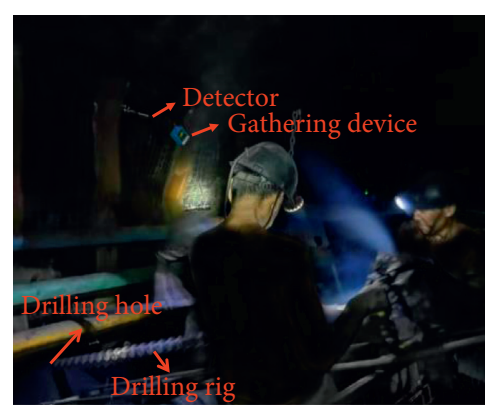

(c)

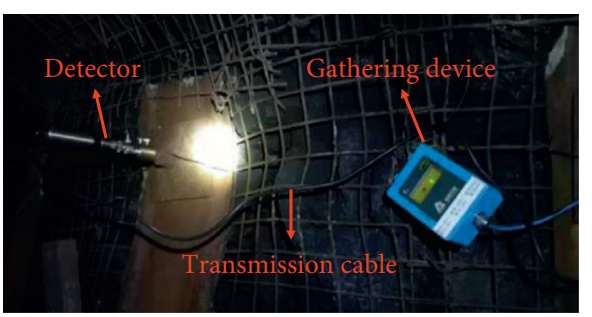

(d)

Figure 1: Test equipment and arrangement. (a) Test arrangement. (b) Hand-held pneumatic drilling rig. (c) Construction site. (d) Site arrangement.

TABle 1: Parameters of the detector.

\begin{tabular}{lc}
\hline Parameters & Parameter values \\
\hline Channel number & $1 \sim 3$ optional \\
Sampling frequency & Single tunnel $1 \sim 7000 \mathrm{~Hz}$ optional and three tunnels $1 \sim 2000 \mathrm{~Hz}$ optional \\
Timing standard & Ground GPS satellite timing \\
Timing equipment & High-precision clock chip \\
Data storage device & Hard disk in device \\
Hard disk capacity & $16 \mathrm{G}$ \\
Battery endurance & More than $96 \mathrm{~h}$ \\
Boundary dimension & $200 \mathrm{~mm} * 280 \mathrm{~mm} * 110 \mathrm{~mm}$ \\
Isolation voltage & $1500 \mathrm{VAC} / 60 \mathrm{~s}$ \\
\hline
\end{tabular}

TABLE 2: Parameters of the gathering device.

\begin{tabular}{lc}
\hline Parameter & Parameter values \\
\hline Type & High-frequency acquisition moving coil speed detector \\
Model & GZC 60 \\
Measuring range & $0 \sim 800 \mathrm{~Hz}$ \\
Sensitivity & $100 \mathrm{~V} / \mathrm{m} / \mathrm{s}$ \\
Normal acceleration & $50 \mathrm{~m} / \mathrm{s}^{2}$ \\
Peak acceleration & $500 \mathrm{~m} / \mathrm{s}^{2}$ \\
Damping coefficient & 0.6 \\
Maximum transmission distance & $50 \mathrm{~m}$ \\
Temperature requirements & High: $60^{\circ} \mathrm{C}$ \\
Humidity requirements & Low: $-40^{\circ} \mathrm{C}$
\end{tabular}

According to the site construction record, the intermissions of $0 \sim 2 \mathrm{~m}, 12 \sim 14 \mathrm{~m}$, and 18 20 $\mathrm{m}$ are caused by drilling interruption, which should be merged. Therefore, there are 10 sets of amplitude group and 9 intermissions, and each set of amplitude group indicates that the drilling distance is $2 \mathrm{~m}$, that is, the drilling depth is $20 \mathrm{~m}$, which is consistent with the actual situation on-site.
As mentioned earlier, the waveform representing vibration events is sharp, which means the amplitude is larger and the change time is shorter. According to this characteristic, 40 vibration events can be found from each waveform measured by the three detectors. The histogram in Figure 5 is used to show the number of vibration events at different drilling depths, from which we can see that the 


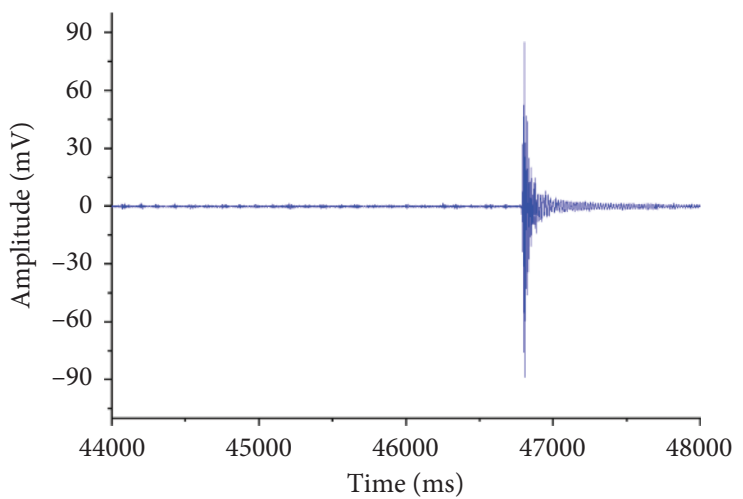

(a)

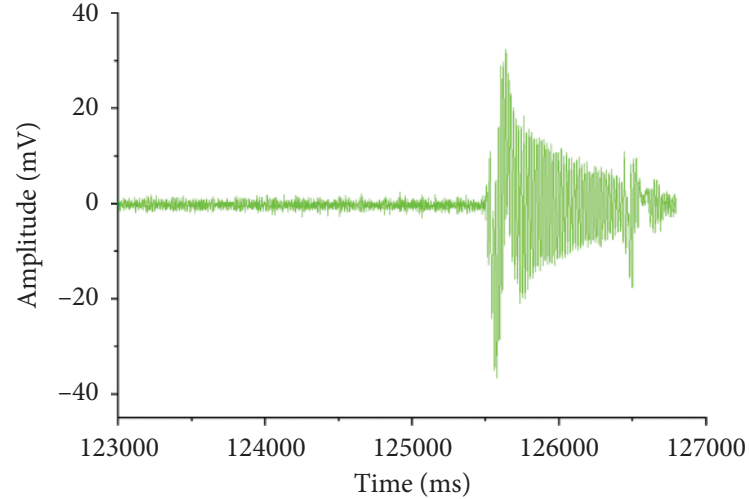

(b)

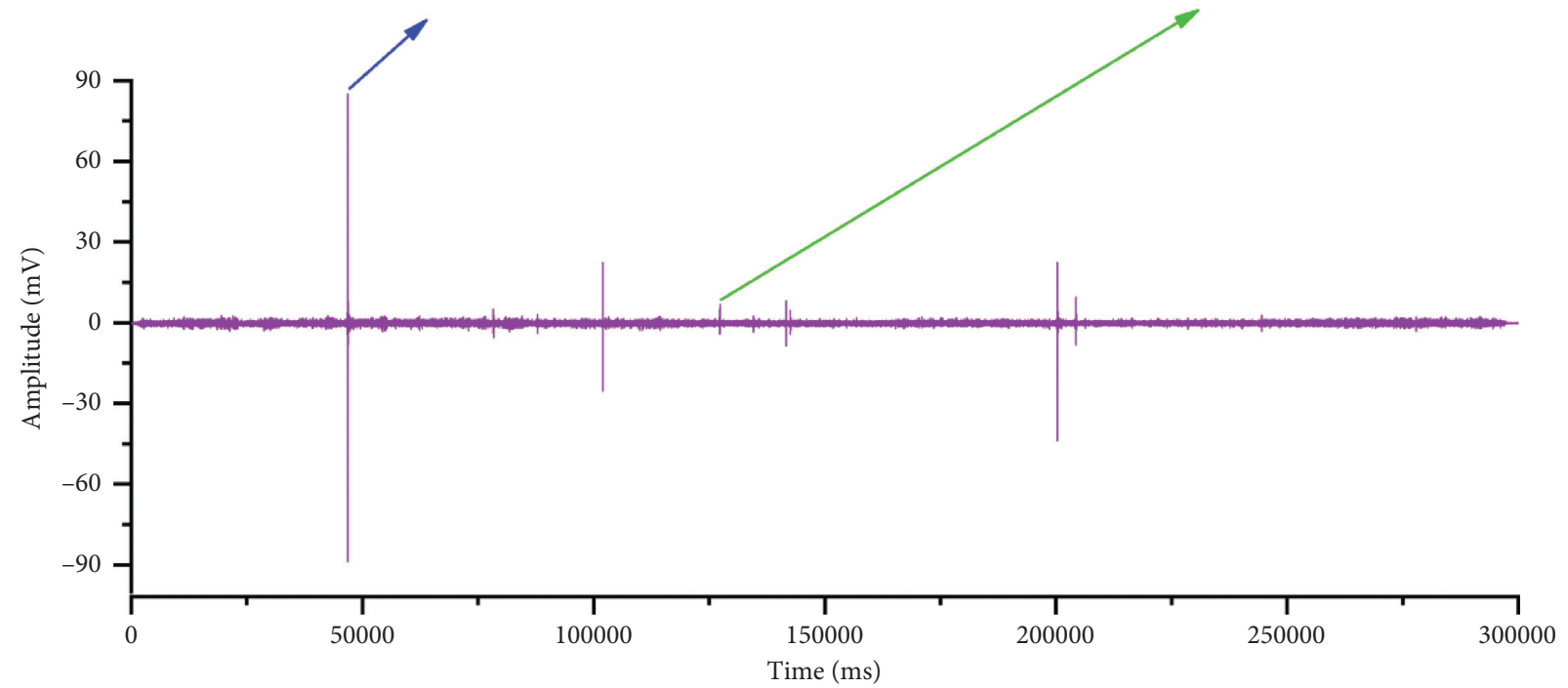

Figure 2: Waveforms measured by 3\# detector. (a) Waveform of vibration event. (b) Waveform of sticking.

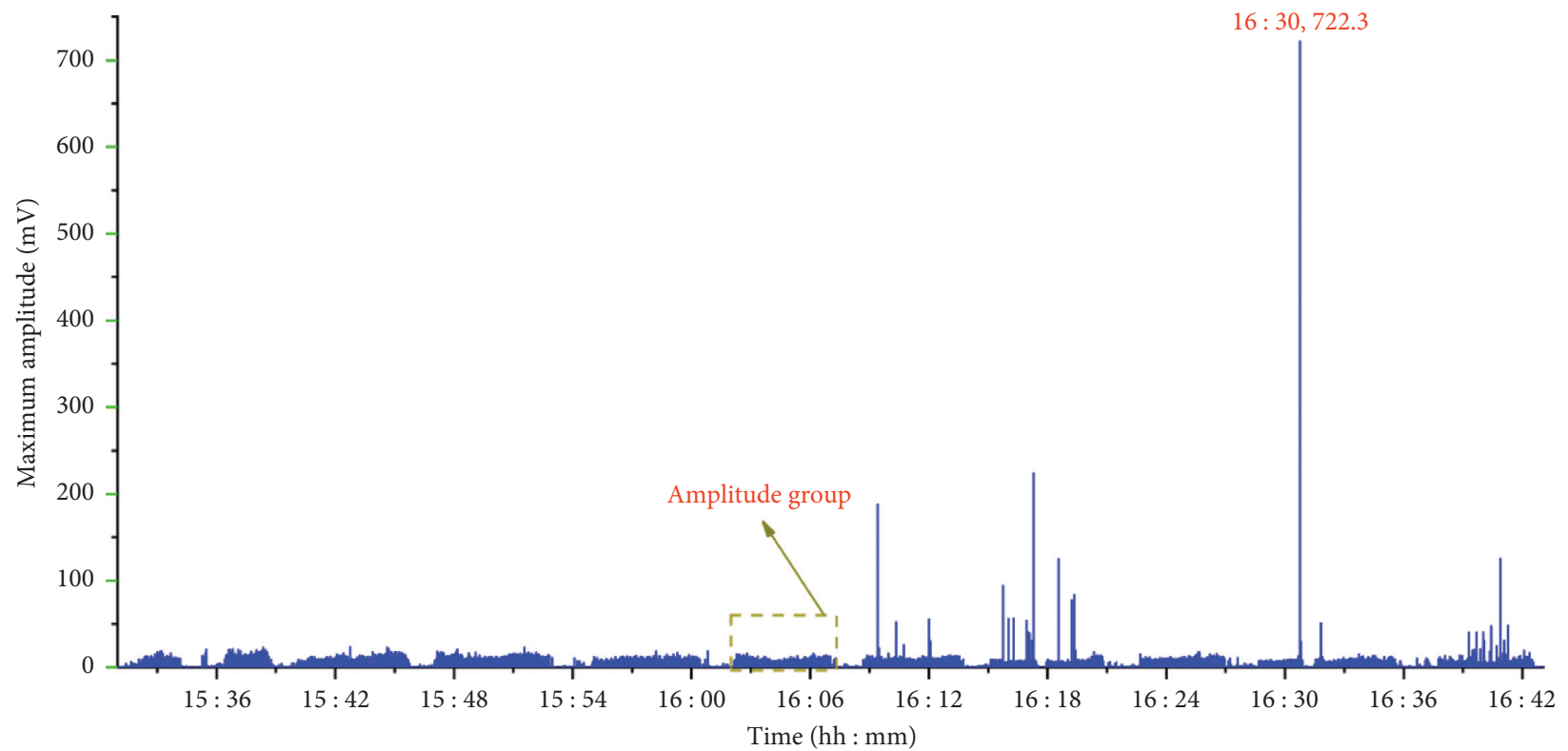

(a)

Figure 3: Continued. 


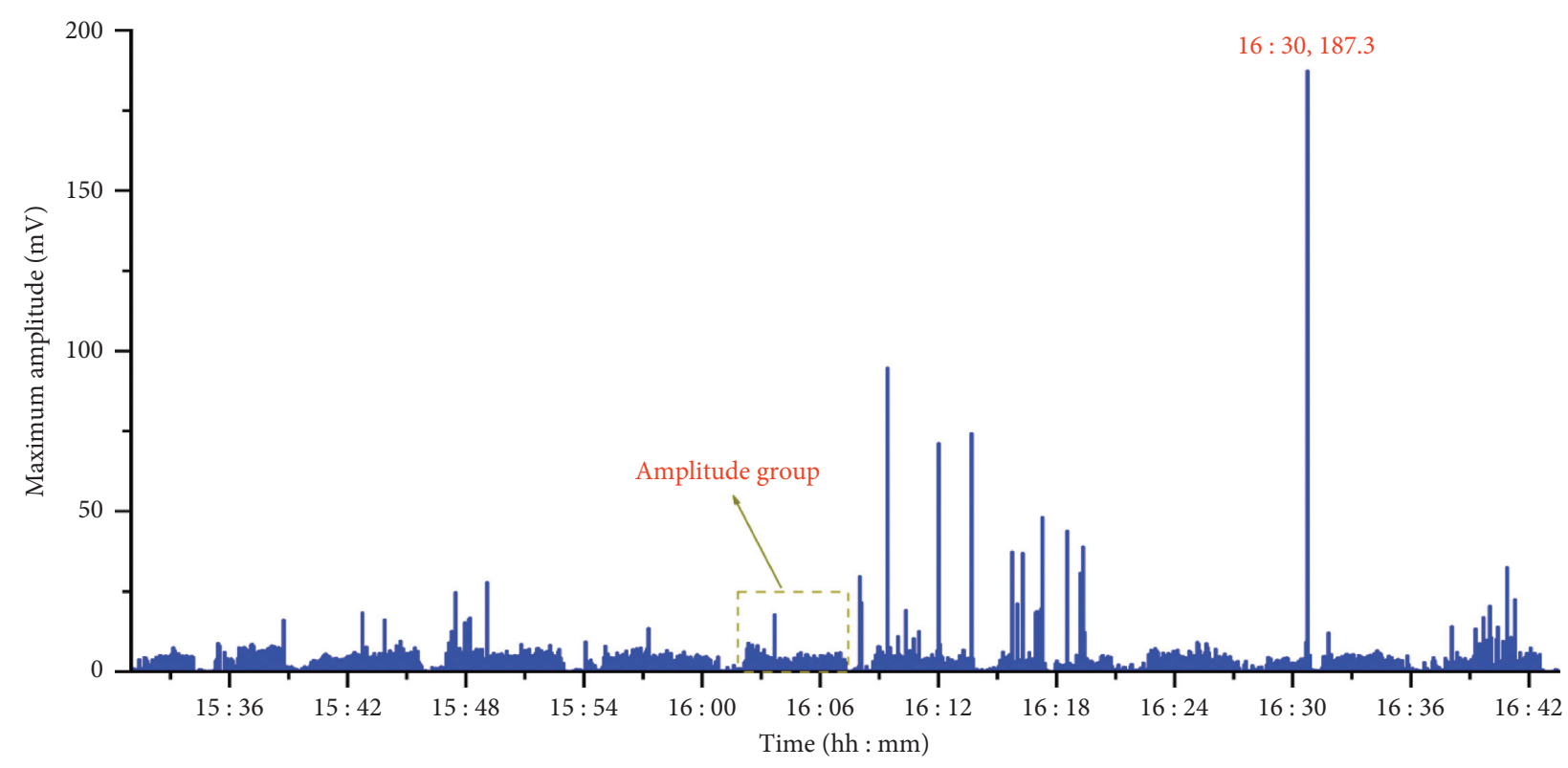

(b)

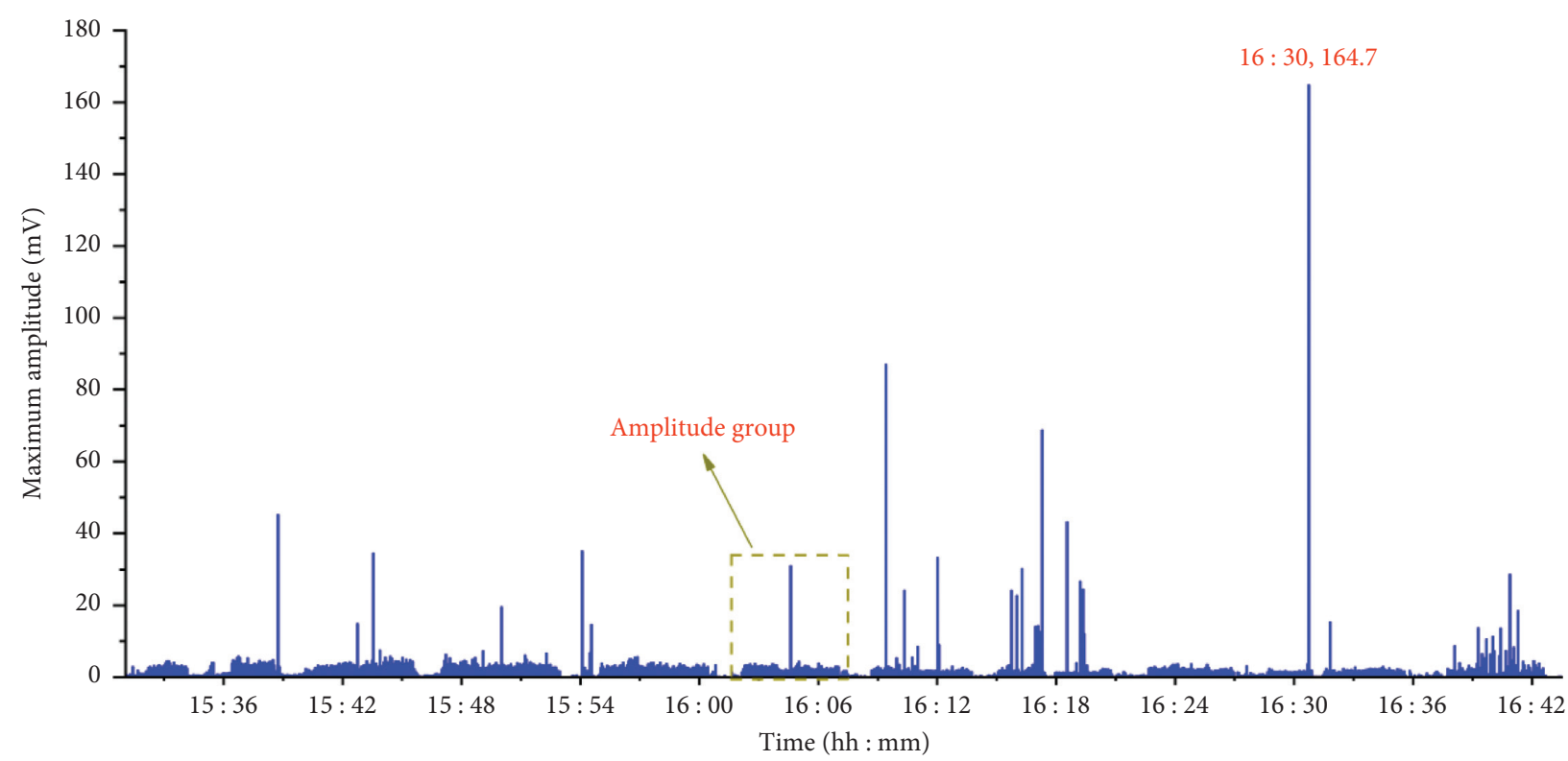

(c)

FIgURE 3: Variation of the maximum amplitude with time. (a) Maximum amplitude tested by $1 \#$ detector. (b) Maximum amplitude tested by 2\# detector. (c) Maximum amplitude tested by $3 \#$ detector.

number of vibration events occurred at drilling depths of $10 \sim 12 \mathrm{~m}, 12 \sim 14 \mathrm{~m}, 16 \sim 18 \mathrm{~m}$, and $18 \sim 20 \mathrm{~m}$ is 5,12 , 2, and 21 , respectively, and no vibration events occur at other depths. The occurrence of vibration events has obvious regional characteristics, that is, some drilling depths have no vibration events, while some others with vibration events happening usually have more. In fact, the more the number of vibration events occurs, the more the energy is released, so the number of vibration events during the construction process can reflect the pressure relief degree at different depths to some extent.

\section{Discussion}

The results show that this method can get the drilling depth and express the vibration events quantitatively. In fact, on the basis of the above analysis, it can also reflect the pressure at different depths. When the driving is difficult, the amplitude of vibration wave is large, so the amplitude can reflect the difficulty of drilling to a certain extent. In this experiment, the average amplitude produced by each drill pipe during construction is used to characterize the construction of coal seam at different depths. The average 


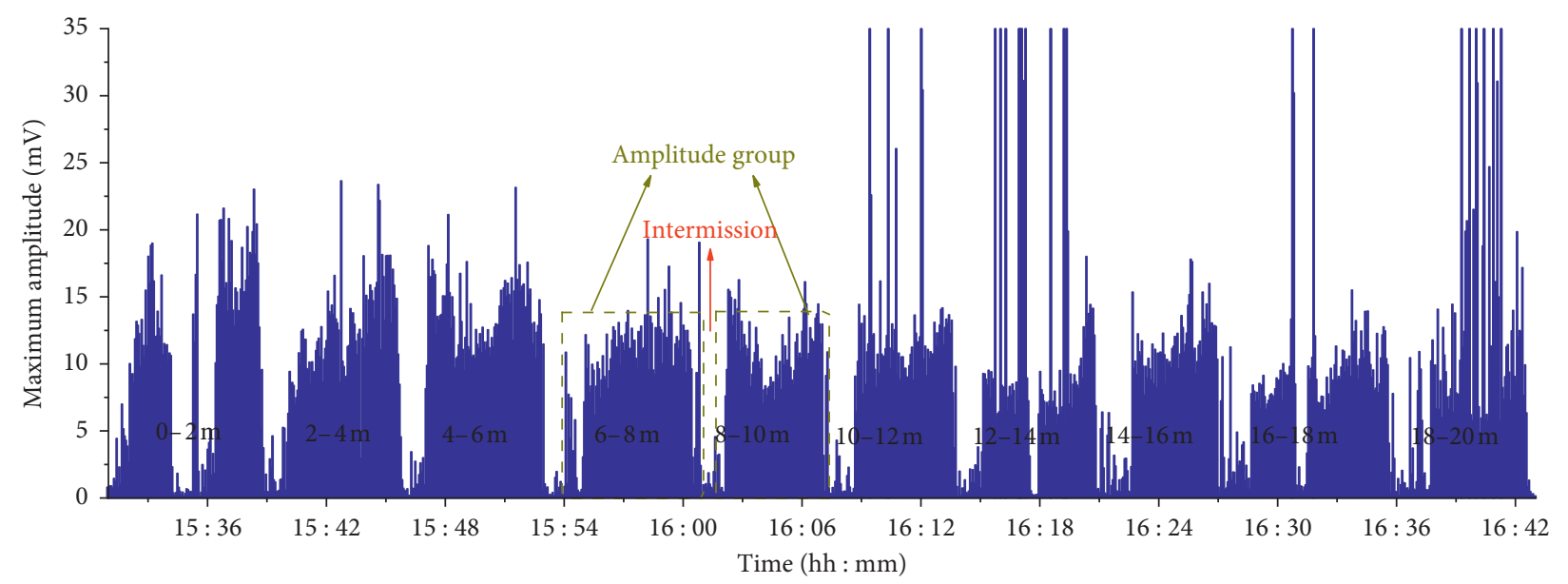

(a)

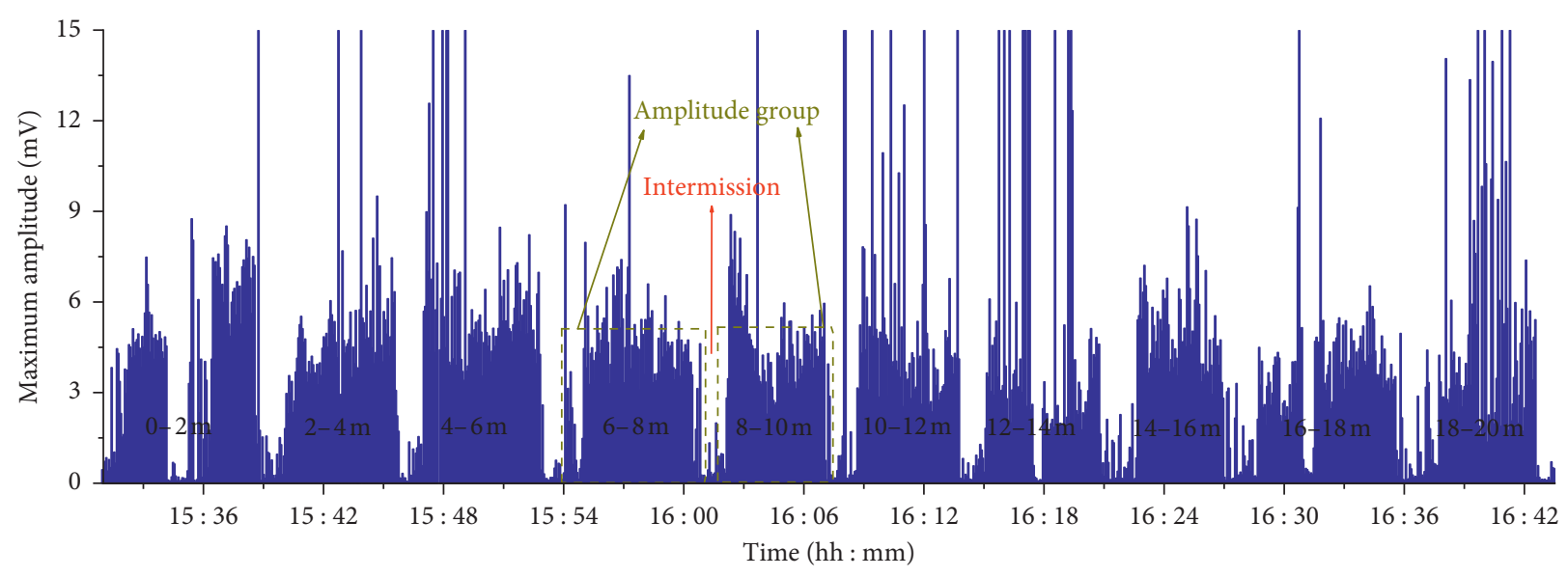

(b)

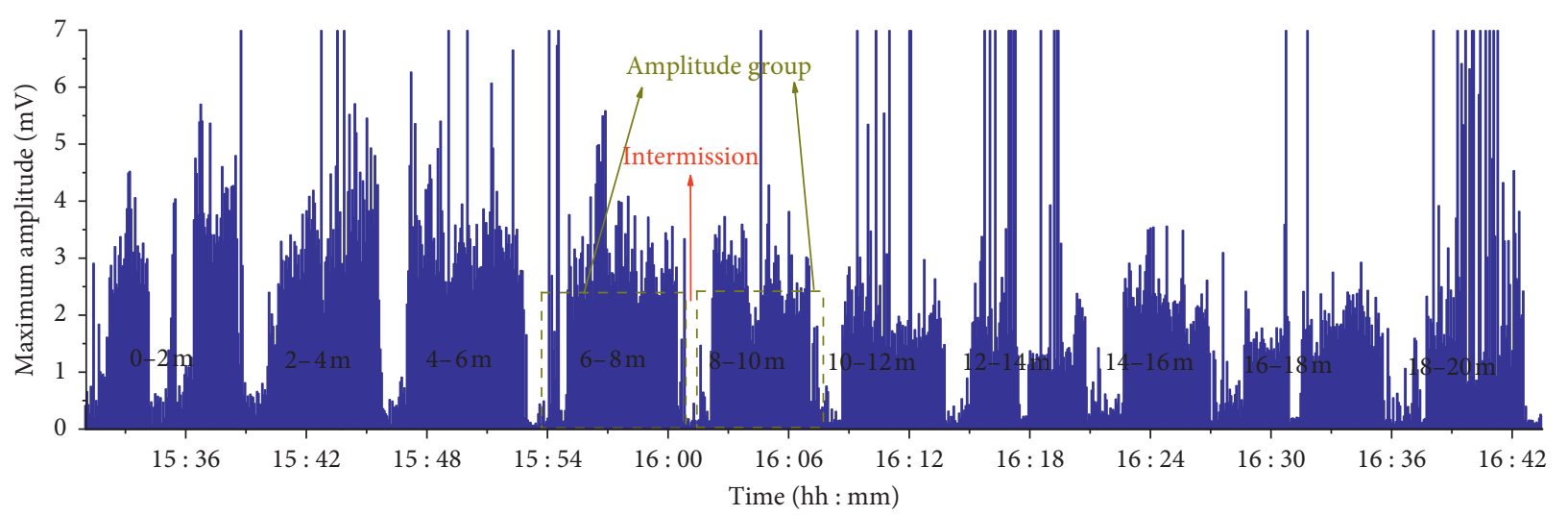

(c)

FIgUre 4: Amplification of maximum amplitude. (a) Amplification diagram of 1\# detector. (b) Amplification diagram of 2\# detector. (c). Amplification diagram of detector 3\#.

amplitude values of each amplitude group measured by the three detectors in the experiment decrease gradually with the increase of the test distance (as shown in Figure 6), which is mainly caused by the propagation characteristics of the vibration wave. Therefore, the measured amplitude values cannot be directly compared to reflect the difficulty of drilling, and they need to be corrected according to the attenuation curve of the vibration wave transmission in the coal seam [41]. The curves of the modified average amplitude measured by the three detectors with drilling distance are shown in Figure 7, which exhibit the same trend basically. The amplitude of 12 14 $\mathrm{m}$ is the lowest and that of $14 \sim 16 \mathrm{~m}$ is the highest, which means that it is relatively easy to drill $12 \sim 14 \mathrm{~m}$, while difficult to drill $14 \sim 16 \mathrm{~m}$. The result that the 


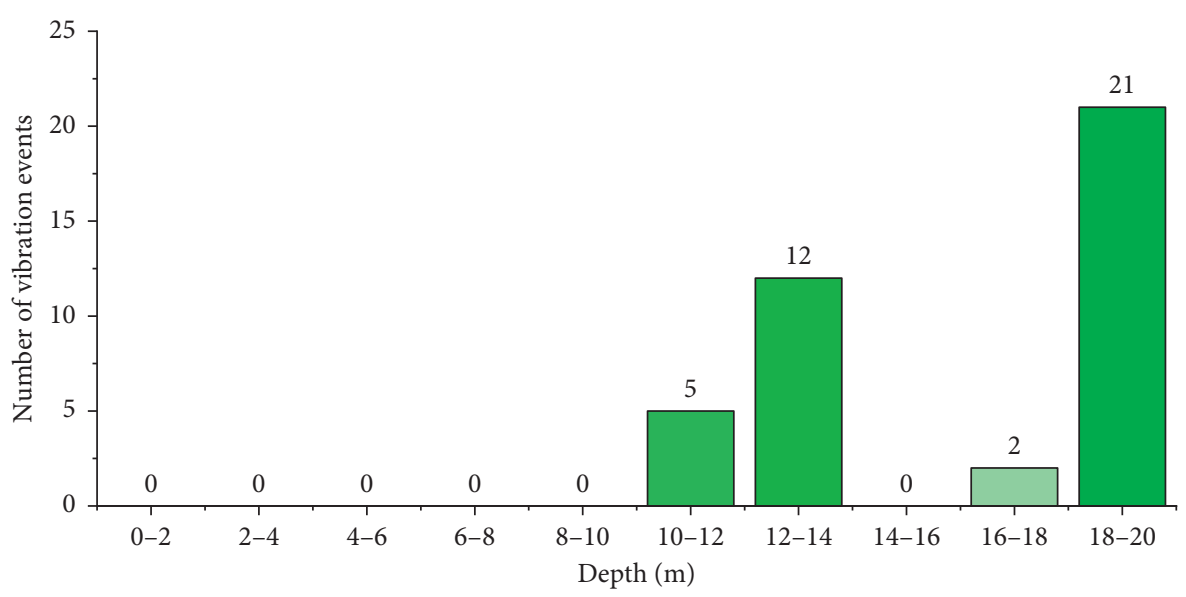

Figure 5: Number of vibration events at different drilling depths.

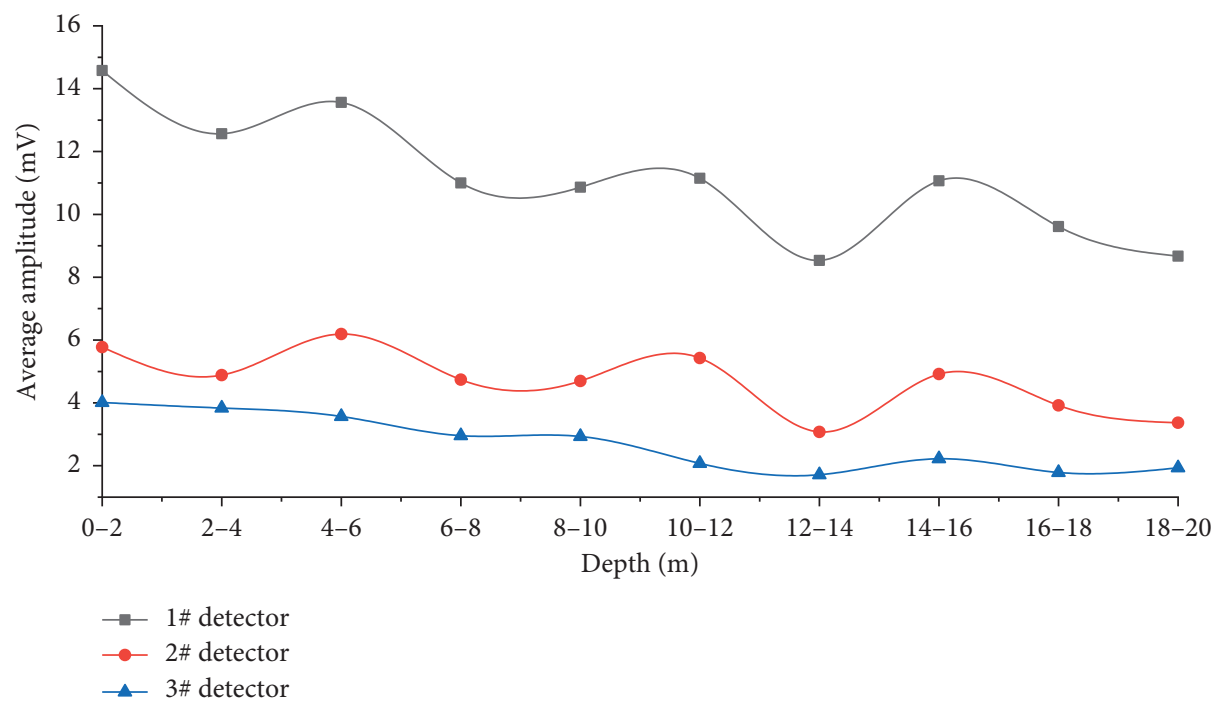

FIGURE 6: Variation curve of average amplitude with drilling depth.

average amplitude value at the depth of $14 \sim 16 \mathrm{~m}$ is the highest is consistent with the field situation of popular the drilling cuttings' method, which indicates that this method has the ability to reflect the pressure at different depths. The comparison between Figures 6 and 7 shows that the signal attenuation has a great influence on the pressure value result, and the attenuation correction must be carried out when it comes to the application of the pressure value.

In order to show the difficulty of constructing each drill pipe, the violin chart of amplitude fluctuation at different depths in Figure 8 is formed. It can be seen that the amplitude fluctuation of $10 \sim 12 \mathrm{~m}, 12 \sim 14 \mathrm{~m}, 16 \sim 18 \mathrm{~m}$, and $18 \sim 20 \mathrm{~m}$ is relatively large and uneven, while the amplitude generated by other drilling depths are relatively uniform. The amplitude generated during $0 \sim 2 \mathrm{~m}$ construction is all within the normal range, and there is no outlier as shown in Figure 8 , which indicates that the geology of the depth is relatively uniform. There are some outliers in the amplitude of $2 \sim 4 \mathrm{~m}, 4 \sim 6 \mathrm{~m}, 6 \sim 8 \mathrm{~m}, 8 \sim 10 \mathrm{~m}$, and $14 \sim 16 \mathrm{~m}$, but the gap among amplitude is not obvious. By analyzing the waveform of outliers, it can be found that these abnormal waveforms are caused by the sticking phenomenon, which indicates that the geological conditions of coal seams at these depths are different, and there is a phenomenon of local stress concentration. The average amplitude of $14 \sim 16 \mathrm{~m}$ in particular is the highest, and most of the amplitude is concentrated near the average value, so it is difficult for workers to construct the drilling at this depth.

The method proposed in this study can quantitatively reflect the drilling depth, which is of great significance for the mine's automatic supervision and inspection of drilling quantities and lays an important foundation for the realization of intelligent mine. In addition to the above effects, this method can also express the number of vibration events at different depths, which can indicate the pressure relief effect to a certain extent. The relationship between amplitude and pressure at different depths is also discussed in this study, the results of which show that amplitude can reflect 


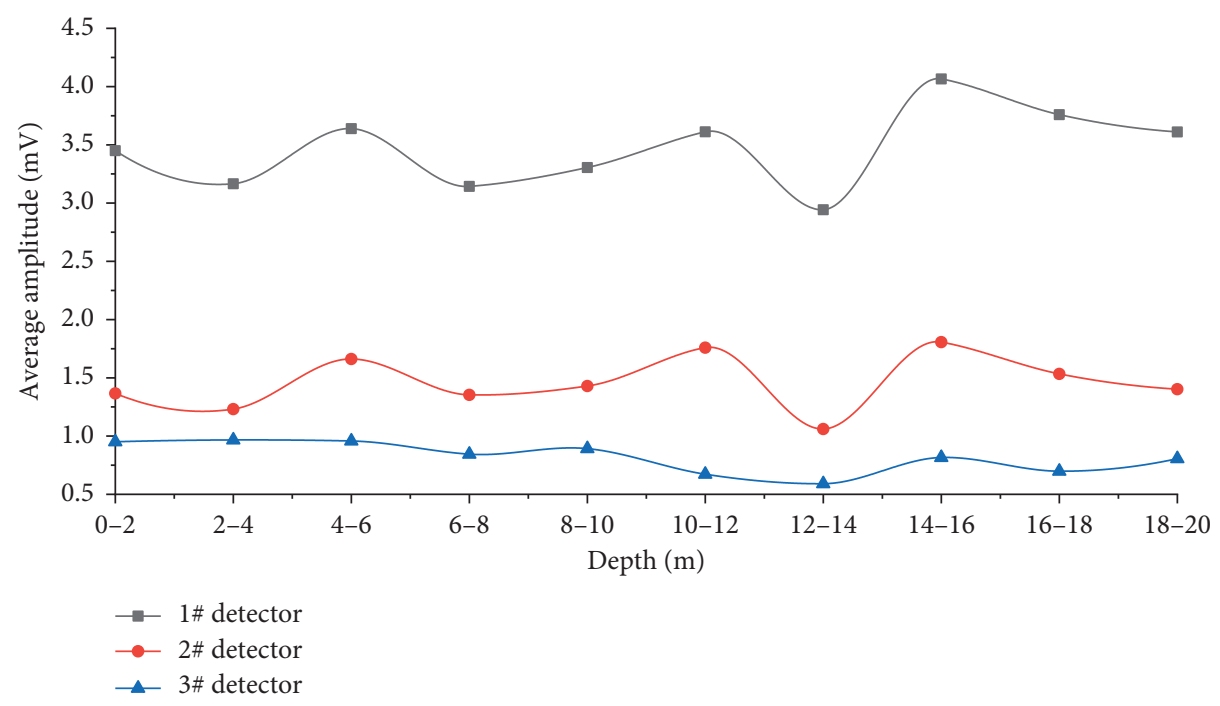

FIgURE 7: Variation curve of the modified amplitude value with drilling depth.

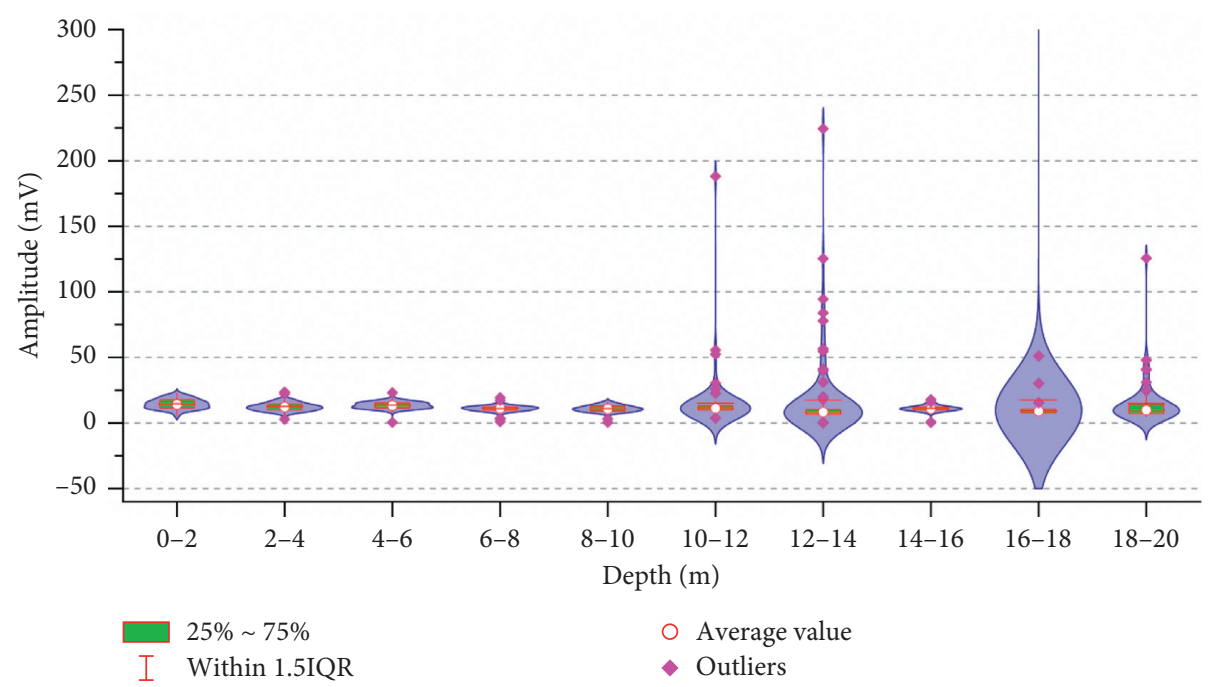

FIGURE 8: Distribution statistics of amplitude values in each amplitude group.

pressure. However, this method has some shortcomings. For example, if the drilling is suspended during constructing one drill pipe due to the workers' operation or other situations on-site, there will be errors in the depth statistics, which leads to errors in the subsequent statistics of vibration events and pressure conditions at different depths. However, from the actual situation of the site, this situation is less and the impact on the error is limited.

\section{Conclusion}

The applicability of the signal acquisition method under the condition of hand-held pneumatic drilling rig is verified by collecting the vibration signal generated during the construction of pressure relief hole in this study. Through the analysis of the test signal, the following information can be obtained: 
(1) The number of amplitude groups can indicate the quantity of construction drill pipes, and the actual depth of pressure relief drilling can be calculated, which is conducive to the intelligent management of mine construction

(2) The average amplitude of different depths and distribution of outliers can reflect the drilling difficulty of different depths and the geological conditions of coal seam

(3) The number of vibration events in different depths can be obtained by statistic on their waveform, which can be used to evaluate the effect of drilling pressure relief holes

\section{Data Availability}

The data used to support the findings of the study are available from the corresponding author upon request.

\section{Conflicts of Interest}

The authors declare that they have no conflicts of interest.

\section{Acknowledgments}

The authors gratefully acknowledge the financial support by the Natural Science Foundation of China (Grant no. 51804159), Science and Technology Innovation and Entrepreneurship Fund of Tiandi Technology Co., Ltd. (2019-TDQN002), and Science and Technology Innovation Fund of CCTEG Coal Mining Research Institute (2020KCMS02 and 2020KCMS03).

\section{References}

[1] C. Meifeng, "Key theories and technonogies for surrounding rock stability and ground control in deep mining," Journal of Mining and Strata Control Engineering, vol. 2, no. 3, 2020.

[2] X. Li, Z. Cao, and Y. Xu, "Characteristics and trends of coal mine safety development," Energy Sources, Part A: Recovery, Utilization, and Environmental Effects, vol. 12, pp. 1-19, 2020.

[3] A. Keneti and B.-A. Sainsbury, "Review of published rockburst events and their contributing factors," Engineering Geology, vol. 246, pp. 361-373, 2018.

[4] B. Hassani, A. Yong, G. M. Atkinson, T. Feng, and L. Meng, "Comparison of site dominant frequency from earthquake and microseismic data in California," Bulletin of the Seismological Society of America, vol. 109, no. 3, pp. 1034-1040, 2019.

[5] C. Mark, "Coal bursts that occur during development: a rock mechanics enigma," International Journal of Mining Science and Technology, vol. 28, no. 1, pp. 35-42, 2018.

[6] L. Jiang, P. Kong, P. Zhang et al., "Dynamic analysis of the rock burst potential of a longwall panel intersecting with a fault," Rock Mechanics and Rock Engineering, vol. 53, no. 4, pp. 1737-1754, 2019.

[7] W. Zhang, N. Ma, J. Ma, C. Li, J. Ren, and B. Jiang, "Mechanism of rock burst revealed by numerical simulation and energy calculation," Shock and Vibration, vol. 2020, pp. 1-15, 2020.
[8] Z. Xiufeng, Q. Xiaocheng, and W. Quande, "Development and application of multi-dimension multi-parameter monitoring and early warning platform of coal bursts," Journal of Mining and Strata Control Engineering, vol. 3, no. 01, pp. 69-78, 2021.

[9] W. Zhang, N. Ma, J. Ren, and C. Li, "Peak particle velocity of vibration events in underground coal mine and their caused stress increment," Measurement, vol. 169, Article ID 108520, 2021.

[10] X. Li, Z. Li, E. Wang et al., "Extraction of microseismic waveforms characteristics prior to rock burst using HilbertHuang transform," Measurement, vol. 91, pp. 101-113, 2016.

[11] W. Zhang, X. Qu, C. Li et al., "Fracture analysis of multi-hard roofs based on microseismic monitoring and control techniques for induced rock burst: a case study," Arabian Journal of Geosciences, vol. 12, no. 24, p. 784, 2019.

[12] L. Dou, J. He, A. Cao, W. Cai, Z. Li, and J. Zhang, "Mechanism and prevention methods discussion on coal mine rock burst induced by dynamic load," in Proceedings of the High Level Academic Forum on the 50th Anniversary of the Founding of China Coal Association.

[13] J. Pan, "Theory of rockburst start - up and its complete technology system," Journal of China Coal Society, vol. 44, no. 1, pp. 173-182, 2019.

[14] N. G. W. Cook, Rock Mechanics Applied to the Study of Rock Burst, J.S.Aft, Johannesburg, South Africa, 1966.

[15] B. G., Kritische Spannungen in Kohlenflozen, Gluckauf, (1975).

[16] K. Ma, C. A. Tang, L. X. Wang et al., "Stability analysis of underground oil storage caverns by an integrated numerical and microseismic monitoring approach," Tunnelling and Underground Space Technology, vol. 54, pp. 81-91, 2016.

[17] X. Liu, D. Fan, Y. Tan et al., "Failure evolution and instability mechanism of surrounding rock for close-distance parallel chambers with super-large section in deep coal mines," International Journal of Geomechanics, vol. 21, no. 5, Article ID 04021049, 2021.

[18] X. Liu, S. Song, Y. Tan et al., "Similar simulation study on the deformation and failure of surrounding rock of a large section chamber group under dynamic loading," International Journal of Mining Science and Technology, vol. 31, no. 3, pp. 495-505, 2021.

[19] W. Zhang, C. Li, J. Jin, X. Qu, S. Fan, and C. xin, "A new monitoring-while-drilling method of large diameter drilling in underground coal mine and their application," Measurement, vol. 173, Article ID 108840, 2021.

[20] X. Liu, C. A. Tang, L. Li, P. Lv, and R. Sun, "Microseismic monitoring and stability analysis of the right bank slope at Dagangshan hydropower station after the initial impoundment," International Journal of Rock Mechanics and Mining Sciences, vol. 108, pp. 128-141, 2018.

[21] C.-P. Lu, L.-M. Dou, N. Zhang et al., "Microseismic frequency-spectrum evolutionary rule of rockburst triggered by roof fall," International Journal of Rock Mechanics and Mining Sciences, vol. 64, pp. 6-16, 2013.

[22] G. Manthei and K. Plenkers, "Review on in situ acoustic emission monitoring in the context of structural health monitoring in mines," Applied Sciences, vol. 8, p. 1595, 2018.

[23] L. Dou, K. Yang, and X. Chi, "Fracture behavior and acoustic emission characteristics of sandstone samples with inclined precracks," International Journal of Coal Science \& Technology, vol. 8, no. 1, pp. 77-87, 2020.

[24] J. Xie, J. Xu, and F. Wang, "Mining-induced stress distribution of the working face in a kilometer-deep coal mine-a case study 
in Tangshan coal mine," Journal of Geophysics and Engineering, vol. 15, no. 5, pp. 2060-2070, 2018.

[25] S. Liu, J. Pan, Y. Xia, Z. Qin, T. Du, and F. Chen, "Research on the risk hierarchical assessment of rock burst of heading face based on acoustic emission and electromagnetic wave CT system," Journal of China Coal Society, vol. 43, 2018.

[26] X. Liu, D. Fan, Y. Tan et al., "New detecting method on the connecting fractured zone above the coal face and a case study," Rock Mechanics and Rock Engineering, vol. 5, 2021.

[27] W. Zhang, C. Li, T. Huo, X. Qu, and C. Xin, "Vibration events in underground heading face and useful index for rock burst monitoring," Measurement, vol. 180, Article ID 109501, 2021.

[28] J. Ning, J. Wang, L. Jiang, N. Jiang, X. Liu, and J. Jiang, "Fracture analysis of double-layer hard and thick roof and the controlling effect on strata behavior: a case study," Engineering Failure Analysis, vol. 81, pp. 117-134, 2017.

[29] Q. Li, B. Lin, and C. Zhai, "The effect of pulse frequency on the fracture extension during hydraulic fracturing," Journal of Natural Gas Science and Engineering, vol. 21, pp. 296-303, 2014.

[30] X. Yongxue, J. Wenjun, S. Shijie et al., "Experimental study on hydraulic reaming of gutters in coal seam with impact pressure," Journal of Mining and Strata Control Engineering, vol. 2, no. 1, pp. 84-91, 2020.

[31] L. Yao and D. Gang, "Reasonable width of narrow coal pillars in roadway driving with gas drainage hole," Journal of Mining and Strata Control Engineering, vol. 2, no. 1, 2020.

[32] C. Li, Z. Wu, W. Zhang, Y. Sun, C. Zhu, and X. Zhang, "A case study on asymmetric deformation mechanism of the reserved roadway under mining influences and its control techniques," Geomechanics and Engineering, vol. 22, no. 5, pp. 449-460, 2020.

[33] Y. Liu, W. Lin, J. Páez Chávez, and R. De Sa, “Torsional stickslip vibrations and multistability in drill-strings," Applied Mathematical Modelling, vol. 76, pp. 545-557, 2019.

[34] S. Srivastava and C. Teodoriu, "An extensive review of laboratory scaled experimental setups for studying drill string vibrations and the way forward," Journal of Petroleum Science and Engineering, vol. 182, Article ID 106272, 2019.

[35] H. Hassani, F. Hloušek, C. Alexandrakis, and S. Buske, "Migration-based microseismic event location in the Schlema-Alberoda mining area," International Journal of Rock Mechanics and Mining Sciences, vol. 110, pp. 161-167, 2018.

[36] M. Babaei Khorzoughi, R. Hall, and D. Apel, "Rock fracture density characterization using measurement while drilling (MWD) techniques," International Journal of Mining Science and Technology, vol. 28, no. 6, pp. 859-864, 2018.

[37] P. Hatherly, R. Leung, S. Scheding, and D. Robinson, "Drill monitoring results reveal geological conditions in blasthole drilling," International Journal of Rock Mechanics and Mining Sciences, vol. 78, pp. 144-154, 2015.

[38] W. Zhang, C. Li, J. Ren, and Z. Wu, "Measurement and application of vibration signals during pressure relief hole construction using microseismic system," Measurement, vol. 158, Article ID 107696, 2020.

[39] C. Zhai, J. Xu, S. Liu, and L. Qin, "Investigation of the discharge law for drill cuttings used for coal outburst prediction based on different borehole diameters under various side stresses," Powder Technology, vol. 325, pp. 396-404, 2018.

[40] L. Zhu, Z. Li, and L. Xu, "Measuring stress and strength of coal by drilling cutting torque method," Chinese Journal of Geotechnical Engineering, vol. 36, pp. 2096-2102, 2014.
[41] Z. Yinhui, W. Guangcai, H. Qianting, and X. Jinpeng, "Theory analysis and experimental study of the spread and attenuation of acoustic emission in rock body," Journal of China Coal Society, vol. 29, Article ID 131762401, 2004. 